\title{
Flexural Responses of Hybrid Steel-Polyethylene Fiber Reinforced Cement Composites Containing High Volume Fly Ash
}

\author{
Shaikh Faiz Uddin Ahmed ${ }^{\mathrm{a}^{*}}$, Mohamed Maalej ${ }^{\mathrm{b}}$, and P. Paramasivam ${ }^{\mathrm{b}}$ \\ ${ }^{a}$ Graduate School of Engineering, Tohoku University, Sendai, Aoba-Ku, 980-8579, Japan. \\ ${ }^{b}$ Dept. of Civil Engineering, National University of Singapore, Blk E1A \#07-03, 1 Engineering \\ Drive 2, Singapore 117576.
}

\begin{abstract}
Strain hardening and multiple cracking behavior of hybrid fiber reinforced cement composites containing different hybrid combinations of steel and polyethylene (PE) fibers under four-point bending are reported. The total volume fraction of fibers was kept constant at $2.5 \%$ to maintain a workable mix. Effects of increase in fly ash content as partial replacement of cement beyond $50 \%$, such as $60 \%$ and $70 \%$ on the flexural response of hybrid steel-PVA (Polyvinyl Alcohol) and steel-PE fiber composites are also evaluated here. Among composites with different volume ratios of steel and PE fibers, the composite with 1.0\% steel and 1.5\% PE was found to show the highest flexural strength and that with $0.5 \%$ steel and 2.0\% PE exhibited highest deflection and highest flexural toughness. Generally, the steel-PE hybrid composites exhibited lower flexural strength but higher deflection capacity than steel-PVA hybrid composites. The rate of strength loss after peak load in steel-PE hybrid composites was found low compared to steel-PVA hybrid system. The $50 \%$ replacement of cement by fly ash is found to be an optimum fly ash content in hybrid fiber composites.
\end{abstract}

Keywords: Hybrid fiber; strain hardening; multiple cracking; toughness; fly ash; Toughness.

*Corresponding author. Tel/fax: +81-22-795-7866; E-mail: shaikhfa@rocketmail.com 


\section{Introduction}

High performance fiber reinforced cementitious composites (FRCC)_exhibiting strain hardening and multiple cracking behavior have been developed. Past research works indicate that strain hardening was mostly achieved in FRCC with high cement content in the matrix such as cement paste and cement mortar [1-5]. The inherent requirement of high cement content in these composites is not only cost prohibitive, but also inconsistent with recent trends in environmental awareness calling for limited cement contents in cementitious materials. Therefore, it is important to develop strain hardening FRCC incorporating cement-replacing materials such as fly ash. The paper by Malhotra [6] clearly explains the role of supplementary cementitious materials in reducing green house gas emissions.

Hybrid fiber FRCC exhibiting strain hardening and multiple cracking behavior have also been developed recently $[7,8]$. In hybrid fiber composites, two or more different types of fibers are suitably combined to exploit their unique properties. The hybridization of fibers in FRCC can be done in different ways, such as by combining different lengths, modulus and tensile strengths of fibers. Large macro fibers bridge the big cracks and provide toughness, while small micro fibers enhance the response prior or just after the cracking. Micro fibers also improve the pull out response of macro fibers, thus produce composites with high strength and toughness [9]. Mono fiber composites containing high modulus fibers normally show high ultimate strength, low strain capacity and small crack width properties [3], while those containing low modulus fibers show low ultimate strength, high strain capacity and large crack width properties [10]. A hybrid composite, with proper volume ratio of high and low modulus fibers, can be expected to show simultaneous improvement in ultimate strength, strain capacity and crack width properties $[7,8]$. 
A number of articles have dealt with the topic of hybrid fiber reinforced cementitious composites. The improvement of mechanical properties such as compressive strength, flexural strength, flexural toughness, tensile strength and impact strength of hybrid fiber reinforced cementitious composites over mono fiber composites and plain concrete has been reported by several researchers [11-16].

The use of fly ash as partial replacement of cement on the development of FRCC has been documented in a number of studies [17-21]. The uses of fly ash in FRCC not only reduce the amount of cement but also help to evenly disperse the fibers during mixing [18]. Experimental results also indicate that interfacial bond strength of fiber and matrix fracture toughness reduce due to the use of fly ash in FRCC [8,20-21]. The low matrix fracture toughness hence the low first crack strength are in favor of strain hardening behavior and low interfacial bond strength of fiber improves the ductility of the composites. The strain hardening and multiple cracking behavior of hybrid fiber FRCC containing high volume fly ash (FA) have been documented in limited number of studies [8,17]. The hybridization of fibers in those studies was done using steel and PVA (Polyvinyl Alcohol) fibers. The fly ash content in those composites was 50\% (partial replacement of cement by weight).

In this study, efforts are being focused on the development of FRCC with strain hardening and multiple cracking behavior in bending using hybrid combinations of steel-PE (polyethylene) fibers containing 50\% fly ash as partial replacement of cement. The effects of increase in fly ash contents (such as 60\% and 70\%) on the strain hardening behavior of hybrid steel-PE and steel-PVA fiber composites are also evaluated. 


\section{Materials and Mix Proportions}

The cement used in this study was ordinary Portland cement which corresponds to ASTM type I. The fly ash was class F fly ash. The physical properties and chemical analysis of cement, fly ash and silica fume are given in Table 1. Properties of steel, polyethylene (PE) and poly vinyl alcohol (PVA) fibers are shown in Table 2. The mix proportions are given in Table 3. Series 1 and 2 are for mono fiber composites containing steel and PE fiber, respectively. Series 3 and 5 are for steel-PE and steel-PVA hybrid fiber composites containing 50\% fly ash (FA) as partial replacement of cement, respectively, while series 4 is for steel-PVA hybrid composites without FA. For each series, three prismatic plate specimens of 300x75x20mm in dimensions were cast and cured for approximately 28 days in fog room. All specimens were tested in fourpoint bending using an Instron testing machine under displacement control with a loading rate of $0.25 \mathrm{~mm} / \mathrm{min}$. A schematic of the bending test setup is shown in Fig. 1. Resulting load versus midspan deflection data were recorded and flexural stress versus deflection curves were plotted.

\section{Results and Discussions}

\subsection{Flexural Behavior of Hybrid Fiber Composites}

The flexural stress versus midspan deflection curves of mono and hybrid fiber composites are shown in Figs. 2-3. The composite with $2.5 \%$ steel (ST) fibers shows high flexural strength but low deflection capacity. On the other hand, the composites with 2.5\% PE or PVA fibers show lower flexural strength but higher deflection capacity that that of steel fiber composites. The highest flexural strength provided by composite with steel fiber is due to its high modulus. In contrast, the high deflection capacity provided by the composite with PE or PVA fiber is due to their low stiffness. 
In case of hybrid fiber composites, the flexural stresses versus midspan deflection curves are found lay between those of steel and PVA or PE mono fiber systems (Figs. 2 and 3). All hybrid fiber composites show increases in both first crack and ultimate strengths with increasing volume fraction of steel fibers. The flexural strength in hybrid fiber composites is found to be higher than that of the composite with PVA or PE fibers alone, while the deflection capacity is found to be higher than that of the composite with steel fibers alone. In this case, the steel fibers maintain their ability to increase the flexural strength of the composite due to their high stiffness and the PVA or PE fibers maintain their ability to increase the deflection capacity of the composite due to their low stiffness.

Flexural stress midspan deflection curves of hybrid fiber composites with different hybrid combinations of steel-PE and steel-PVA fibers are shown in Figs. 4-6. By looking into these figures, it can be noticed that steel-PVA hybrid composites showed higher flexural strength than that of steel-PE hybrid composites. Published experimental data suggests that PVA fiber has higher bond strength than that of PE fiber [22-23]. For a crack-bridging fiber, the bridging stress is resisted by the interfacial bond stress (frictional bond as well as chemical bond) between the fiber and the matrix. Hence, the higher bond strength of PVA fibers than that of PE fibers resulted in higher flexural strength of steel-PVA hybrid composites observed in this experiment.

In every cases, steel-PE hybrid composites exhibited higher deflection capacity than those of steel-PVA hybrid system. Due to high tensile strength, PE fibers bridged the wide cracks without being ruptured resulted in high deflection capacity and low rate of strength loss after the peak load. On the other hand, the rate of strength loss in hybrid steel-PVA system was higher than steel-PE hybrid system. This is probably due to the low strength of PVA fiber. 
Because as soon as the cracks widen the PVA fibers, which bridge the cracks, ruptured due to its higher bond strength and lower tensile strength than that of PE fiber resulted in higher rate of strength loss after the peak load.

Table 4 summarizes the toughness indices for mono and hybrid fiber composites. The toughness index represents the area under the load deflection curve up to a given deflection divided by the area under the same curve up to first cracking [24]. Depending on the deflection capacity of the specimen, different toughness indices $I_{5}, I_{10}, I_{30}, I_{50}, I_{100}$ and $I_{\text {failure }}$ as defined by ASTM C1018-Standard test method for flexural toughness and first crack strength of fiberreinforced concrete-were used to characterize the flexural toughness [24]. Table 4 shows that the toughness indices for all hybrid fiber composites increase with increasing steel fiber content. Toughness indices values as high as 186 were observed in the hybrid fiber composite containing 0.5\% steel and 2.0\% PE fibers. Naaman and Reinhardt [25] pointed out that fiber reinforced composites having toughness indices $\mathrm{I}_{5}>5, \mathrm{I}_{10}>10$, and $\mathrm{I}_{30}>30$ etc. can be termed as strainhardening type materials. From Table 4, it appears that all hybrid fiber composites studied in this investigation meet the above criteria and can therefore be classified as strain-hardening composites. Evidence for the strain-hardening behavior in these materials can also be seen from the multiple cracking patterns shown in Fig. 7.

\subsection{Effect of high volume fly ash on strain-hardening behavior of hybrid composites}

The effects of increase in fly ash contents beyond 50\% i.e. 60\% and 70\% replacement of cement by fly ash on the strain hardening and multiple cracking behavior of hybrid steel-PVA and steel-PE fiber composites are evaluated in this study. The effect of no fly ash on the strain hardening and multiple cracking behavior of hybrid steel-PVA fiber composites is also evaluated 
in this study and are compared with those containing 50\% fly ash. The flexural stress-midspan deflection curves for steel-PVA hybrid fiber composites with 50\% fly ash and without fly ash are plotted in Fig. 8 and 9, respectively. The inclusion of 50\% fly ash as partial replacement of cement slightly reduces the flexural strength but greatly increases the midspan deflection at peak load of steel-PVA hybrid fiber composites (Figs. 10 and 11). The multiple cracking is also enhanced by the inclusion of fly ash as can be seen by comparing Figs. 12 and 13 . The inclusion of high volume fly ash in cement mortar increases the composite's porosity, this has been confirmed in the present study, where the porosity of hybrid steel-PVA fiber composites with $50 \%$ fly ash was found higher than that without fly ash as determined using the mercury intrusion porosimetery (MIP) (Fig. 14). Increased porosity of PAN and glass fiber reinforced composites with fly ash was also reported by Peled et al. [21]. The increase in composite's porosity decreases the bond strength of fibers and this may explain the reduction in flexural strength and improvement in deflection capacity of hybrid steel-PVA fiber composite containing $50 \%$ fly ash. The toughness indices for steel-PVA hybrid composites with 50\% fly ash are also higher that those without fly ash (Series 4 and 5 in Table 4).

The effects of further increase in fly ash contents beyond $50 \%$, such as $60 \%$ and $70 \%$, on flexural strength and deflection capacities of hybrid steel-PE and steel-PVA composites are also evaluated (Figs. 15 and 16). With regard to the flexural strength of hybrid fiber composites no improvement in the flexural strength is observed when $60 \%$ and $70 \%$ fly ash was used rather a slight decrease in flexural strength can be seen in both steel-PVA and steel-PE hybrid composites (Figs. 10 and 15). A similar trend can also be observed in case of deflection capacity 
at peak load (Figs. 11 and 16). Therefore, it suggests that the 50\% replacement of cement by fly ash can be considered as an optimum content of fly as for use in hybrid fiber composites.

\section{Conclusions}

This paper presented the results of an experimental investigation on the strainhardening behavior of hybrid steel-PE fiber composites under four-point bending. Comparison with hybrid steel-PVA fiber composites is also presented. Hybrid steel-PE fiber composites showed lower ultimate strength but higher deflection capacity at peak load than that of hybrid steel-PVA fiber composites. Strain-hardening behavior accompanied by multiple cracking was achieved in all hybrid steel-PE fiber composites in this study. Hybrid combination of $1.5 \%$ steel and 1.0\% PVA exhibited best performance in terms of highest flexural strength, $0.5 \%$ steel and 2.0\% PE exhibited highest deflection and energy absorption capacities. Rate of strength loss after peak load in hybrid steel-PE composites was found to be lower than that of steel-PVA hybrid composites. The $50 \%$ replacement of cement by fly ash is found to be an optimum fly ash content in hybrid fiber composites.

\section{Acknowledgement}

The first author would like to acknowledge the financial assistance in term of Graduate Research Scholarship from the National University of Singapore.

\section{References}

[1]T. Kanda, Z. Lin and V.C. Li, Tensile Stress-Strain Modeling of Pseudo StrainHardening Cementitious Composite, Journal of Materials in Civil Engineering, ASCE, 2000; 12(2):147-156. 
[ 2]T. Kanda and V.C. Li, New micromechanics design theory for pseudostrain hardening cementitious composite, Journal of Engineering mechanics, ASCE, 1999; 125(4):373381.

[ 3]V.C. Li, H.C. Wu, M. Maalej, D.K. Mishra and T. Hashida, Tensile Behavior of Engineered Cementitious Composites with Discontinuous Random Steel Fibers. Journal of American Ceramic Society, 1996; 79(1): 74-78.

[ 4] V.C. Li, S. Wang and C. Wu, Tensile Strain Hardening Behavior of Polyvinyl Alcohol Engineered Cementitious Composites (PVA-ECC), ACI Materials Journal, 2001; 98(6): 483-492.

[ 5]P. Tjiptobroto and W. Hansen, Tensile strain-hardening and multiple cracking in high performance cement based composites containing discontinuous fibers, ACI Materials Journal, 1993; 90(1): 16-25.

[ 6]V.M. Malhotra, Role of Supplementary Cementing Materials in Reducing Greenhouse Gas Emissions; MTL 98-03 (OP\&J), International workshop on Concrete Technology for Sustainable Development in the 21st Century, Norway, June 24-27, 1998.

[ 7]S.F.U. Ahmed, M. Maalej and P. Paramasivam, Analytical Model for Tensile Strain Hardening and Multiple Cracking Behavior of Hybrid Fiber Engineered Cementitious Composites, (2005) (Submitted for publication in ASCE, Journal of materials in civil engineering).

[ 8]S.F.U. Ahmed, M. Maalej and P. Paramasivam, Strain-hardening Behavior of Hybrid Fiber Reinforced Cement Composites, Journal of Ferrocement 2003; 33 (3): 172-182. 
[ 9]N. Banthia and N. Nandakumar, Crack growth resistance of hybrid fiber reinforced cement composites, Cement and Concrete Composite 2003; 25: 3-9.

[ 10] M. Maalej, T. Hashida and V. C. Li, Effect of Fiber Volume Fraction on the OffCrack-Plane Fracture Energy in Strain-hardening Engineered Cementitious Composites; Journal of American Ceramic Society 1995; 78 (12): 3369-3375.

[11] K. Komlos, B. Babal,, and T. Nurnbergerova, Hybrid fiber reinforced concrete under repeated loading, Nuclear Engineering and Design 1995; 156:195-200.

[12] N. Banthia, A. Moncef, K. Chokri, and J. Sheng, Microfiber reinforced cement composites. I: Uniaxial tensile response, Canadian Journal of Civil Engineering 1994; 21: 999-1010.

[13] B. Mobasher and C.Y. Li, Mechanical properties of hybrid cement based composites, ACI Materials Journal 1996; 93 (3): 284-292.

[ 14] W. Yao, J. Li and K. Wu, Mechanical properties of hybrid fiber reinforced concrete at low fiber volume fraction, Cement and Concrete Research 2003; 33: 27-30.

[ 15] M. Nehdi and J. D. Ladanchuk, Fiber synergy in fiber reinforced self consolidating concrete, ACI Materials Journal 2004; 101(6): 508-517.

[ 16] Cyr, M.F, Peled, A. and Shah, S.P., Extruded hybrid fiber reinforced cementitious composites, In the proceedings of the Seventh International Symposium on Ferrocement and Thin Reinforced Cement Composites, ed. Mansur, M.A. and Ong, G., Singapore, 2001 p. 199-207. 
[ 17] N. Ramanalingam, P. Paramasivam, M.A. Mansur, and M. Maalej, Flexural behavior of hybrid fiber reinforced cement composites containing high volume fly ash, Proceedings of the $7^{\text {th }}$ CANMET/ACI international Conference, 2001, ACI SP-199.

[ 18] C.X. Qian and P. Stroeven, Development of hybrid polypropylene-steel fiber reinforced concrete, Cement and Concrete Research 2000; 30: 63-69.

[ 19] Y. Zhang, W. Sun, L. Shang and G. Pan, The effect of high content of fly ash on the properties of glass fiber reinforced cementitious composites, Cement and Concrete Research 1997; 27(12): 1885-1891

[ 20] V.C. Li, M. Lepech, S. wang, M. Weimann and G. Keoleian, Development of green engineered cementitious composites for sustainable infrastructure systems, Proceedings of the international workshop on sustainable development and concrete technology, Beijing, 2004: 181-191.

[21] A. Peled, M.F. Cyr, and S.P. Shah, High content of fly ash (class F) in extruded cementitious composites, ACI materials journal 2000; 97 (5): 509-517.

[ 22] T. Kanda, and V.C. Li, New micromechanics design theory for pseudo strain hardening cementitious composites, ASCE Journal of Engineering Mechanics 1999; 125 (4): 373381.

[23] T. Kanda, and V.C. Li, Interface property and apparent strength of high-strength hydrophilic fiber in cement matrix, ASCE Journal of Materials in Civil Engineering 1998; 10 (1): 5-13. 
[ 24] "Standard test method for flexural toughness and first crack strength of fiber reinforced concrete (Using beam with third-point loading)”, ASTM C 1018 (American Society for Testing and Materials), 1997.

[25] A.E. Naaman and H.W. Reinhardt, Characterization of high performance fiber reinforced cement composites, Proceedings of the Second International RILEM Workshop, USA, June 1995, p. 1-24. 
Table 1

Physical Properties and Chemical Composition of Cementitious Materials

\begin{tabular}{|c|c|c|c|}
\hline Properties & $\mathrm{OPC}$ & FA & SF \\
\hline Type/ class & ASTM Type I & ASTM Class F & - \\
\hline \multicolumn{4}{|l|}{ Physical Properties: } \\
\hline Specific Gravity & 3.17 & 2.68 & 2.00 \\
\hline \multicolumn{4}{|l|}{ Fineness } \\
\hline Passing $45 \mu \mathrm{m}$ sieve (\%) & - & $90 \%$ & - \\
\hline Retained on $150 \mu \mathrm{m}$ sieve (\%) & - & $1 \%$ & - \\
\hline Surface area, Blaine $\left(\mathrm{cm}^{2} / \mathrm{gm}\right)$ & 3170 & - & 250000 \\
\hline \multicolumn{4}{|l|}{ Chemical Analysis: } \\
\hline $\mathrm{SiO}_{2}$ & 21.10 & 55.2 & 93.0 \\
\hline $\mathrm{Al}_{2} \mathrm{O}_{3}$ & 5.24 & 25.3 & 0.2 \\
\hline $\mathrm{Fe}_{2} \mathrm{O}_{3}$ & 3.10 & 8.34 & 0.05 \\
\hline $\mathrm{CaO}$ & 64.39 & 2.65 & - \\
\hline $\mathrm{MgO}$ & 1.10 & 1.56 & 0.51 \\
\hline $\mathrm{SO}_{3}$ & 2.52 & 0.09 & 0.05 \\
\hline $\mathrm{Na}_{2} \mathrm{O}$ & 0.23 & 0.58 & 0.2 \\
\hline $\mathrm{K}_{2} \mathrm{O}$ & 0.57 & 1.39 & 0.22 \\
\hline LOI & 1.22 & 1.6 & 4.15 \\
\hline
\end{tabular}

Note: OPC: Ordinary Portland cement; FA: Fly ash; SF: Silica Fume

Table 2

Properties of fibers

\begin{tabular}{ccccccc}
\hline $\begin{array}{c}\text { Fiber } \\
\text { types }\end{array}$ & $\begin{array}{c}\text { Length } \\
\left(\mathrm{L}_{\mathrm{f}}\right)\end{array}$ & $\begin{array}{c}\text { Diameter } \\
\left(\mathrm{d}_{\mathrm{f}}\right)\end{array}$ & $\begin{array}{c}\text { Aspect } \\
\text { ratio } \\
\left(\mathrm{L}_{\mathrm{f}} / \mathrm{d}_{\mathrm{f}}\right)\end{array}$ & $\begin{array}{c}\text { Modulus of } \\
\text { elasticity } \\
\left(\mathrm{E}_{\mathrm{f}}\right) \mathrm{GPa}\end{array}$ & $\begin{array}{c}\text { Fiber strength, } \\
\mathrm{MPa}\end{array}$ & $\begin{array}{c}\text { Fiber } \\
\text { density } \\
\mathrm{gm} / \mathrm{cm}^{3}\end{array}$ \\
\hline Steel & 13 & 160 & 81 & 200 & 2500 & 7.8 \\
PVA $^{\mathrm{a}}$ & 12 & 40 & 300 & 44 & 1850 & 1.3 \\
PE & 12 & 39 & 308 & 79 & 2610 & 0.97 \\
\hline
\end{tabular}

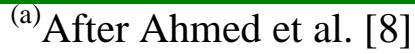


Table 3

Mix proportions of hybrid fiber composites

\begin{tabular}{lllllllll}
\hline \multirow{2}{*}{ Series } & \multicolumn{7}{l}{ Fibers (\%) } & \multicolumn{7}{l}{ Mix Proportions } \\
\cline { 2 - 8 } & Steel & PVA & PE & Cement & Fly ash & $\begin{array}{l}\text { Water/ } \\
\text { Binder }\end{array}$ & $\begin{array}{l}\text { Sand/ } \\
\text { Binder }\end{array}$ & $\begin{array}{l}\text { Silica Fume/ } \\
\text { Binder }\end{array}$ \\
\hline 1 & 2.5 & - & - & 0.5 & 0.5 & 0.45 & 1.0 & 0.05 \\
2 & - & - & 2.5 & 0.5 & 0.5 & 0.45 & 1.0 & 0.05 \\
\hline 3 & 0.5 & - & 2.0 & 0.5 & 0.5 & 0.45 & 1.0 & 0.05 \\
& 1.0 & - & 1.5 & 0.5 & 0.5 & 0.45 & 1.0 & 0.05 \\
& 1.5 & - & 1.0 & 0.5 & 0.5 & 0.45 & 1.0 & 0.05 \\
\hline 4 & 0.5 & 2.0 & - & 1.0 & - & 0.45 & 1.0 & 0.05 \\
& 1.0 & 1.5 & - & 1.0 & - & 0.45 & 1.0 & 0.05 \\
& 1.5 & 1.0 & - & 1.0 & - & 0.45 & 1.0 & 0.05 \\
\hline $5^{*}$ & 0.5 & 2.0 & - & 0.5 & 0.5 & 0.45 & 1.0 & 0.05 \\
& 1.0 & 1.5 & - & 0.5 & 0.5 & 0.45 & 1.0 & 0.05 \\
& 1.5 & 1.0 & - & 0.5 & 0.5 & 0.45 & 1.0 & 0.05 \\
\hline
\end{tabular}

*Ahmed et al [8]

Table 4

Toughness indices of mono and hybrid fiber composites

\begin{tabular}{|c|c|c|c|c|c|c|c|c|c|c|}
\hline \multirow[t]{2}{*}{ Series } & \multirow[t]{2}{*}{ Fiber Type } & \multirow{2}{*}{$\begin{array}{c}\mathrm{V}_{\mathrm{f}}^{\text {Steel }} \\
(\%)\end{array}$} & \multirow{2}{*}{$\begin{array}{c}\mathrm{V}_{\mathrm{f}}^{\mathrm{PVA}} \\
(\%)\end{array}$} & \multirow{2}{*}{$\begin{array}{l}\mathrm{V}_{\mathrm{f}}^{\mathrm{PE}} \\
(\%)\end{array}$} & \multirow[b]{2}{*}{$\mathrm{I}_{5}$} & \multicolumn{4}{|c|}{ Toughness Indices } & \multirow[b]{2}{*}{$\mathrm{I}_{\text {failure }}$} \\
\hline & & & & & & $\mathrm{I}_{10}$ & $\mathrm{I}_{30}$ & $\mathrm{I}_{50}$ & $\mathrm{I}_{100}$ & \\
\hline 1 & Steel & 2.5 & - & - & 6.6 & 15.0 & 43.5 & - & - & 48.8 \\
\hline 2 & $\mathrm{PE}$ & - & - & 2.5 & 5.5 & 11.8 & 42.7 & 66.1 & - & 66.1 \\
\hline \multirow{3}{*}{3} & Steel and & 0.5 & - & 2.0 & 5.1 & 10.1 & 34.5 & 79.1 & - & 186 \\
\hline & $\mathrm{PE}$ & 1.0 & - & 1.5 & 5.3 & 10.1 & 34.6 & 59.9 & - & 69.9 \\
\hline & Hybrid & 1.5 & - & 1.0 & 5.9 & 12.1 & 40.6 & 67.8 & - & 97.6 \\
\hline \multirow[t]{3}{*}{4} & Steel and & 0.5 & 2.0 & - & 4.8 & 9.2 & 19.9 & - & - & 22.3 \\
\hline & PVA & 1.0 & 1.5 & - & 6.4 & 13.9 & 53.9 & - & - & 61.0 \\
\hline & Hybrid & 1.5 & 1.0 & - & 7.7 & 13.5 & 32.4 & - & - & 37.6 \\
\hline \multirow[t]{3}{*}{$5 *$} & Steel and & 0.5 & 2.0 & - & 4.95 & 10.4 & 38.6 & 67.5 & - & 72.4 \\
\hline & PVA & 1.0 & 1.5 & - & 5.05 & 11.5 & 40.9 & 74.9 & - & 135 \\
\hline & Hybrid & 1.5 & 1.0 & - & 5.50 & 12.9 & 45.1 & 75.1 & - & 75.1 \\
\hline
\end{tabular}

*Ahmed et al [8] 


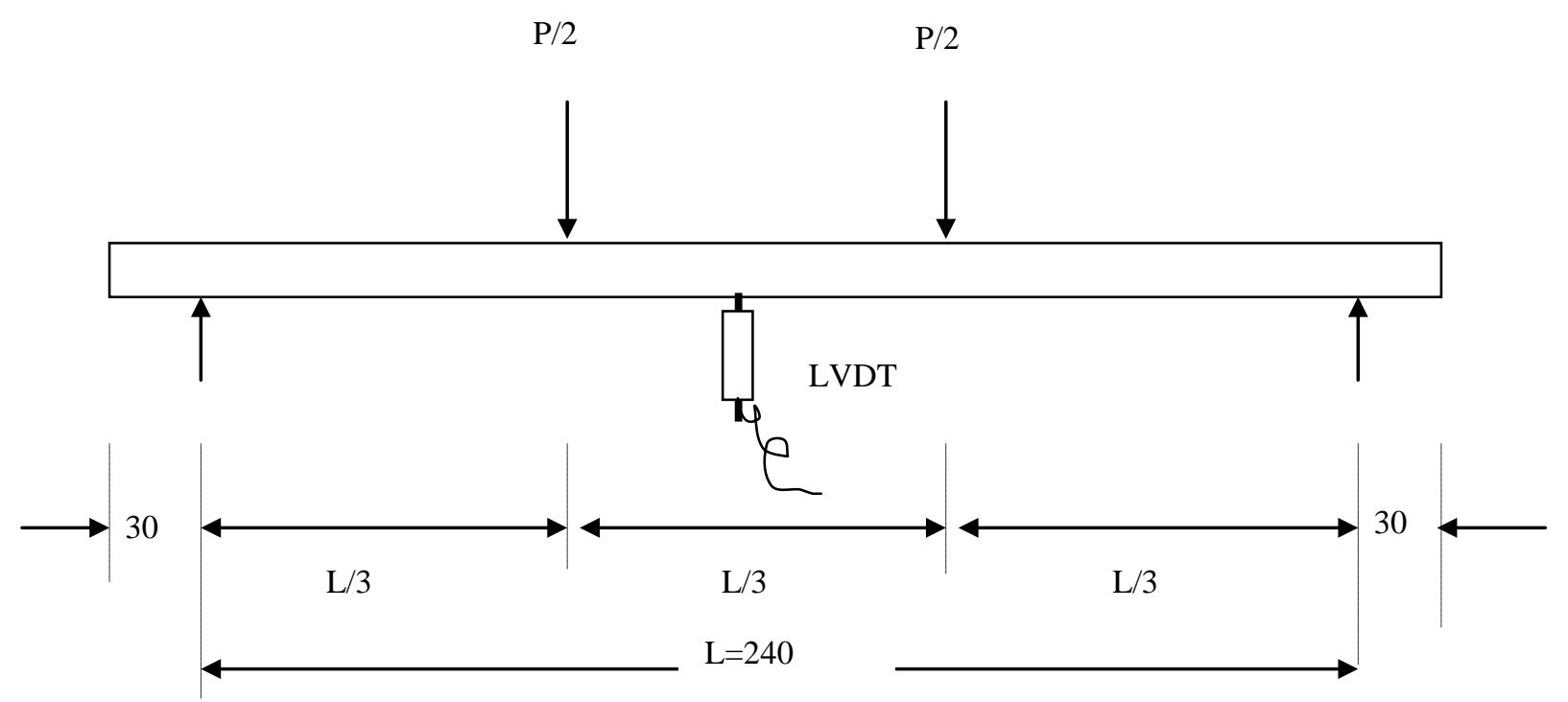

Fig. 1 Schematic of bending test set-up (all dimensions in $\mathrm{mm}$ ).

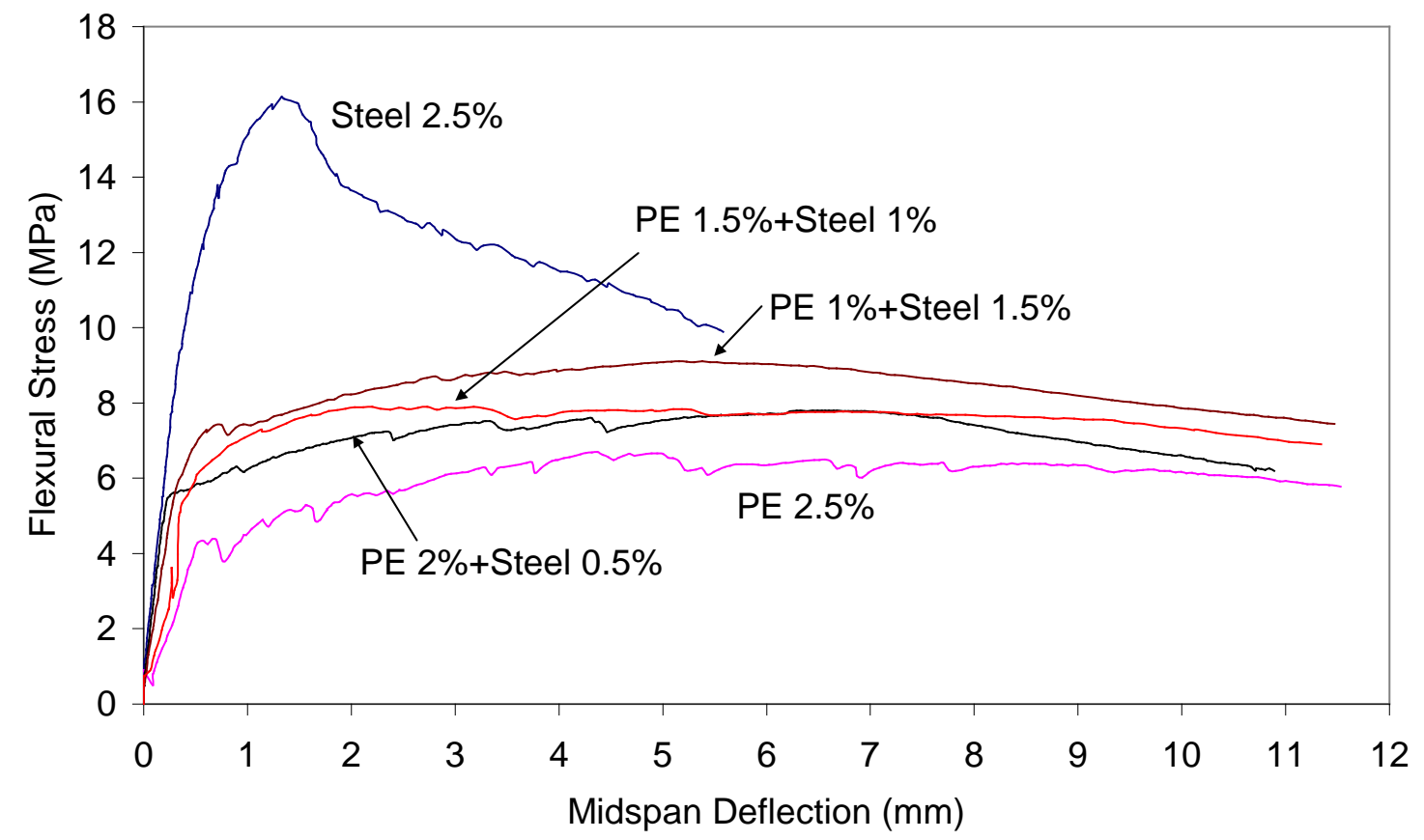

Fig. 2 Flexural stress - mid span deflection curves for hybrid steel-PE fiber composites. 


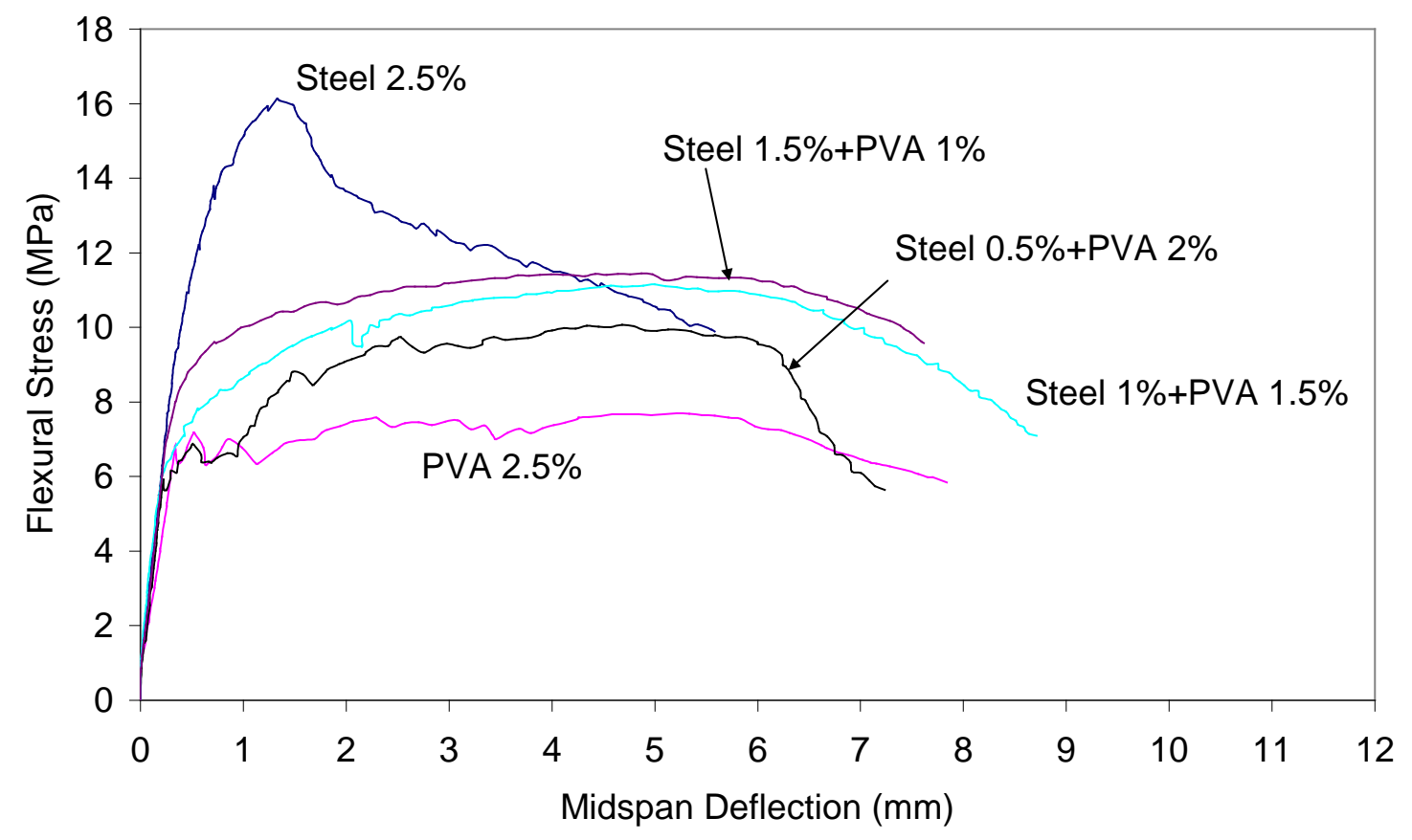

Fig. 3 Flexural stress - mid span deflection curves for hybrid steel-PVA fiber composites. (After Ahmed et al. [8])

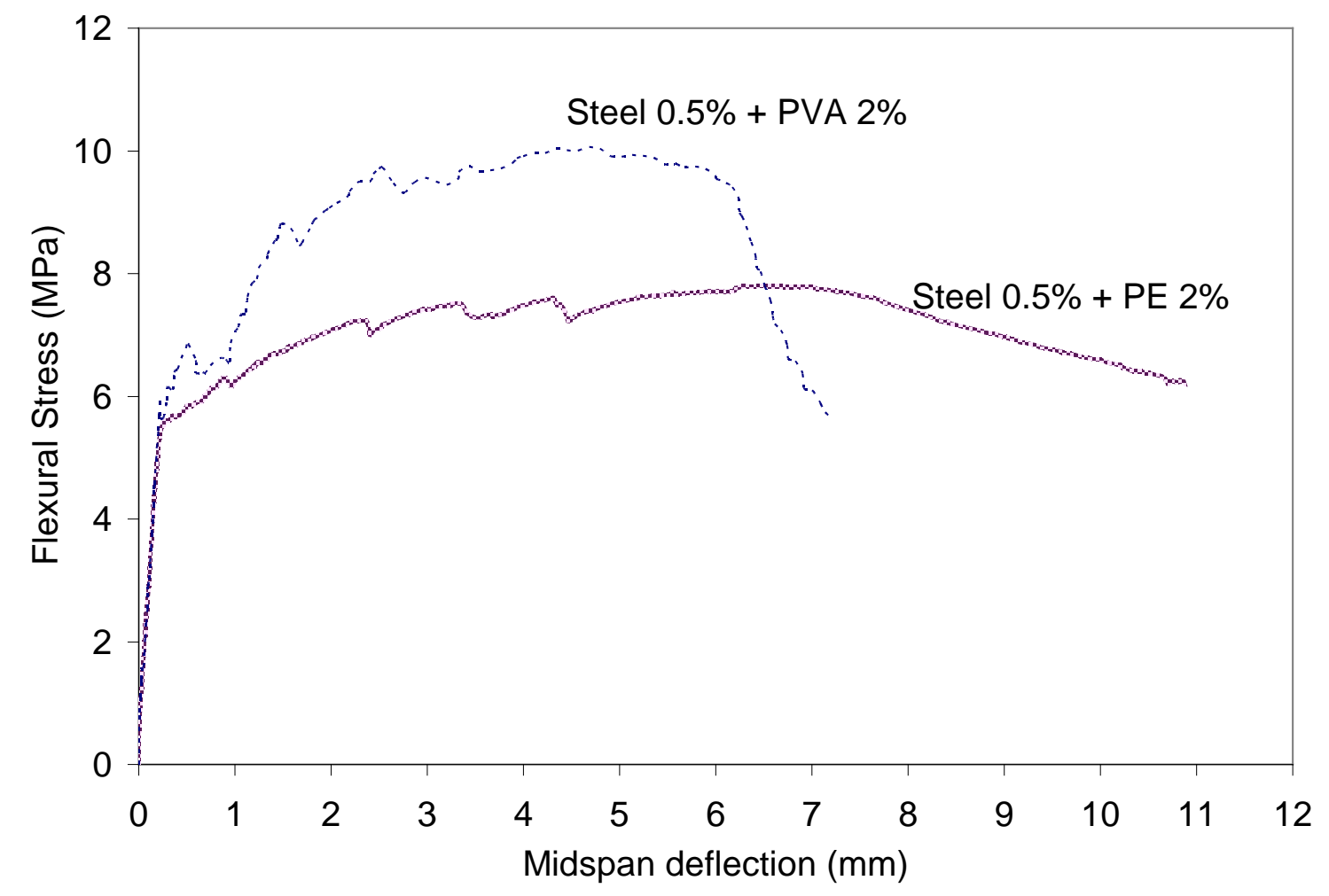

Fig. 4 Flexural stress - mid span deflection curves for hybrid composites containing $0.5 \%$ steel and 2\% PVA or PE fibers. 


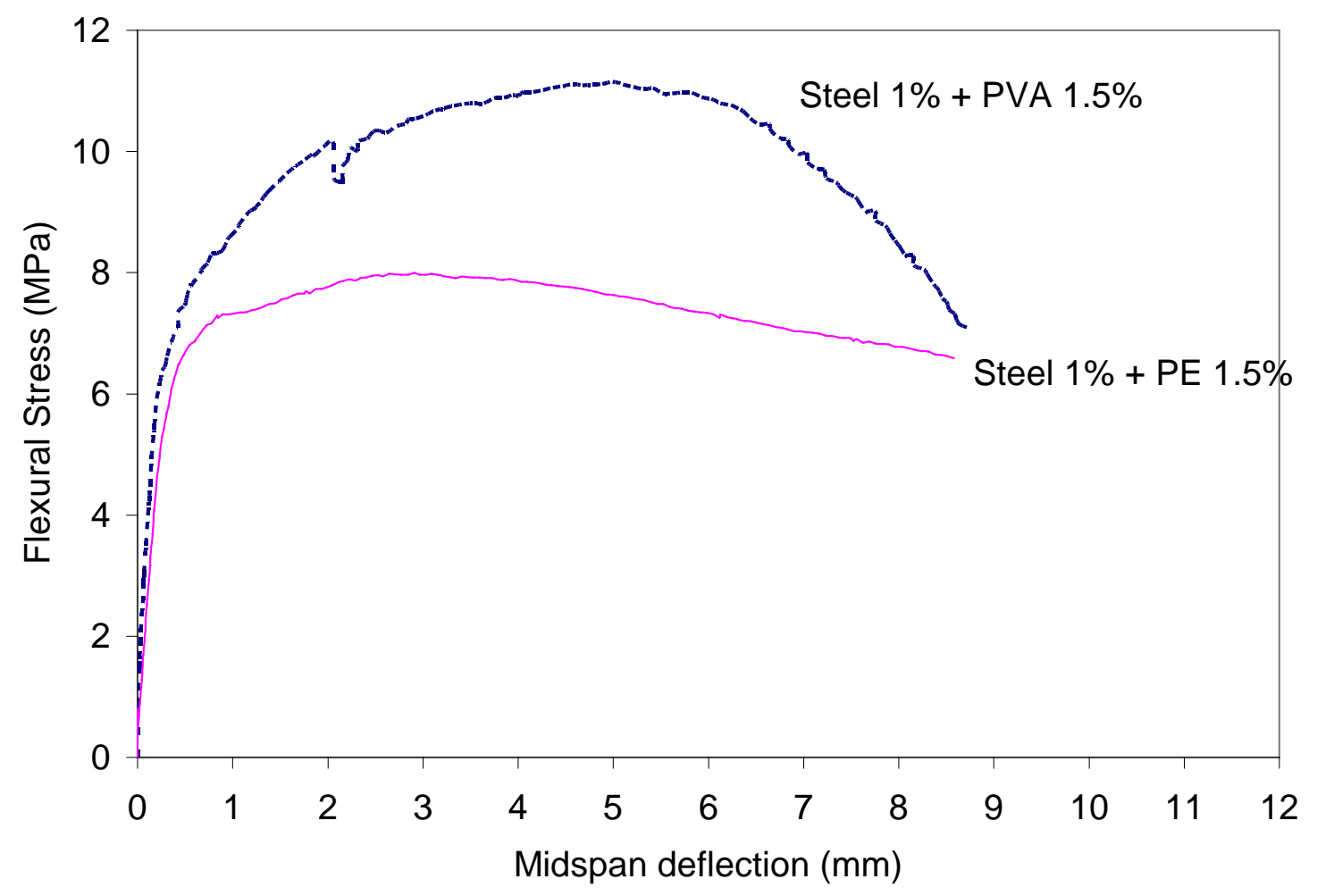

Fig. 5 Flexural stress - mid span deflection curves for hybrid composites containing 1.0\% steel and 1.5\% PVA or PE fibers.

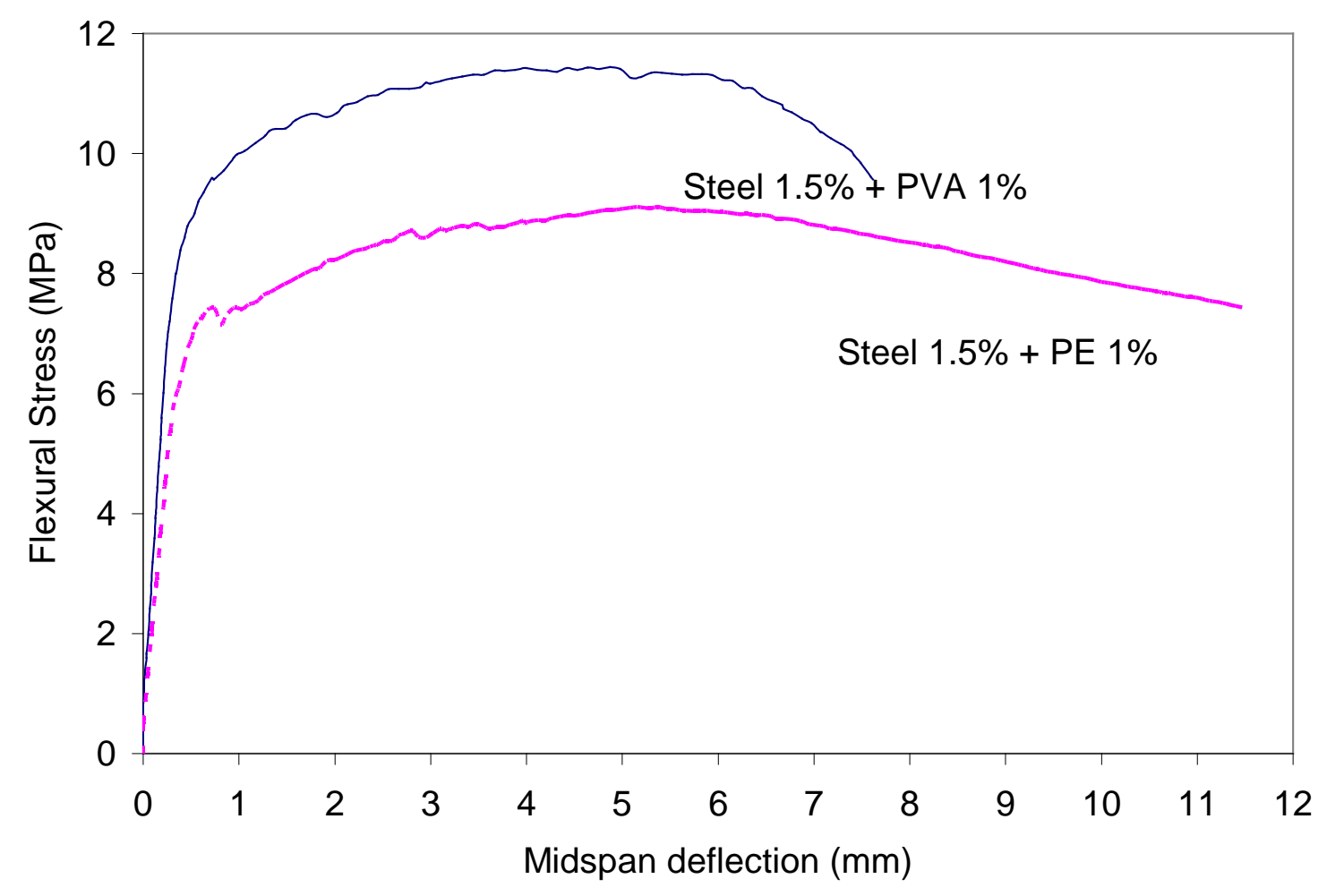

Fig. 6 Flexural stress - mid span deflection curves for hybrid composites containing 1.5\% steel and 1.0\% PVA or PE fibers. 


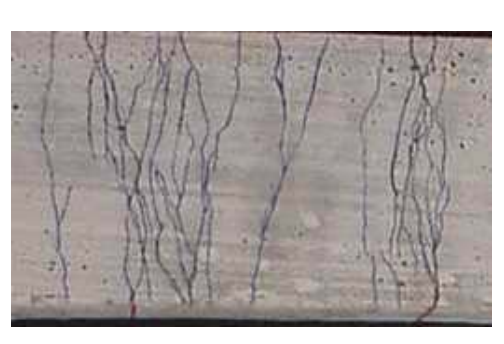

Steel 1.5+ PE1.0

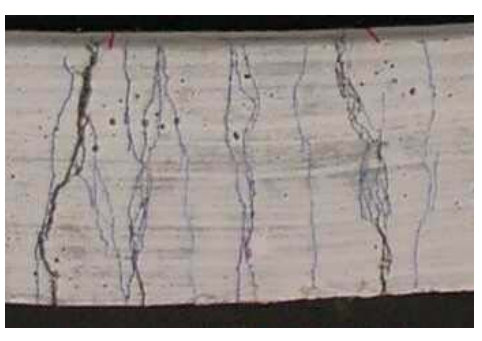

Steel 1.0+ PE 1.5

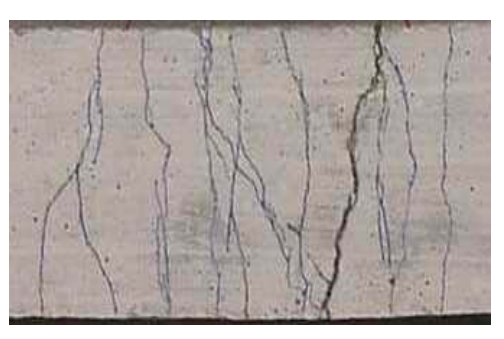

Steel 0.5+PE2.0

Fig.7 Multiple cracking of steel-PE hybrid fiber composites containing 50\% fly ash as partial replacement of cement.

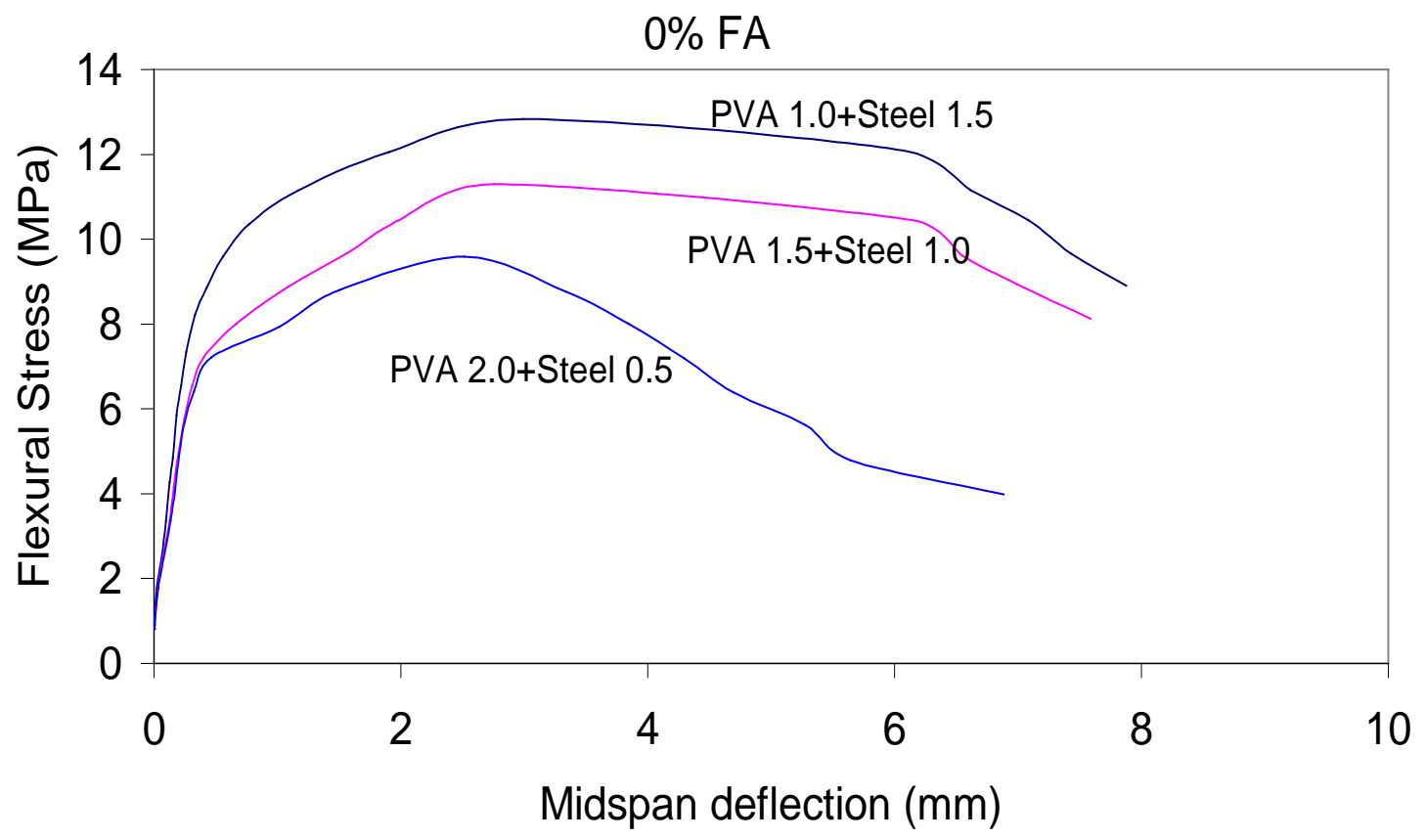

Fig. 8 Flexural stress - mid span deflection curves for hybrid steel-PVA fiber composites containing no fly ash. (Note: FA denotes Fly ash) 


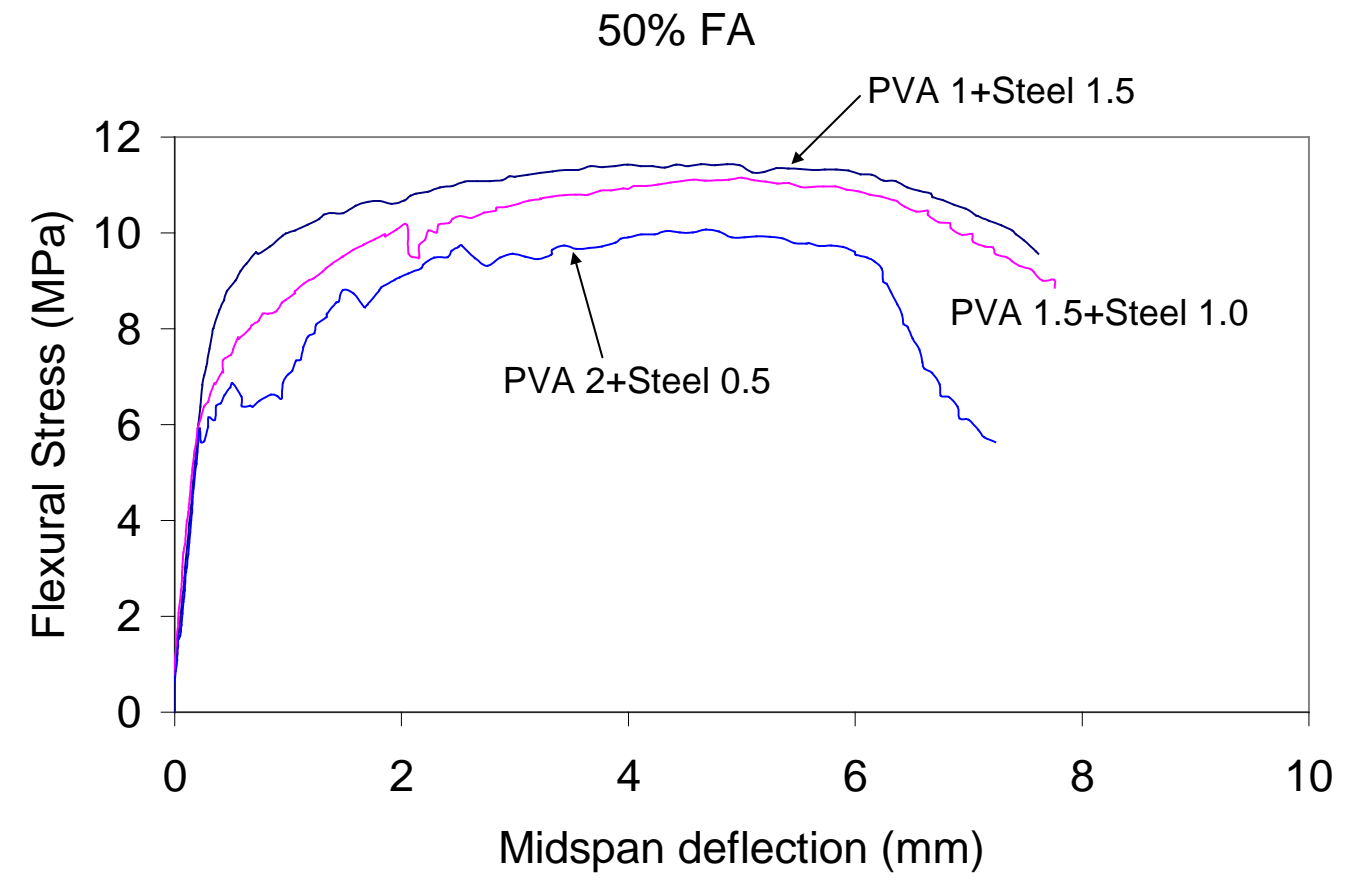

Fig. 9 Flexural stress - mid span deflection curves for hybrid steel-PVA fiber composites containing $50 \%$ fly ash as partial replacement of cement. (Note: FA denotes Fly ash) (After Ahmed et al. [8])

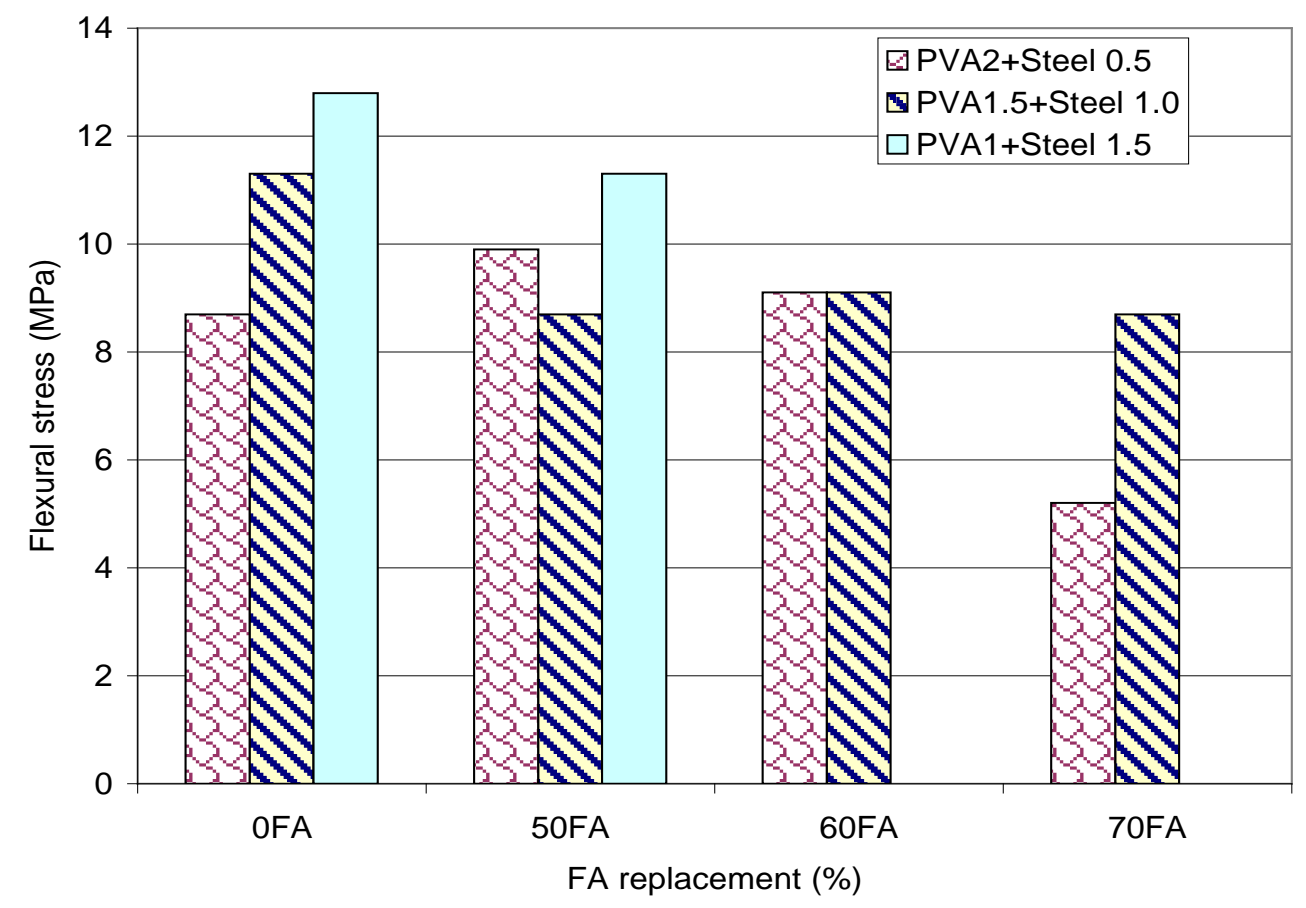

Fig. 10 Ultimate flexural strength of steel-PVA hybrid composites with and without fly ash. (Note: FA denotes Fly ash) 


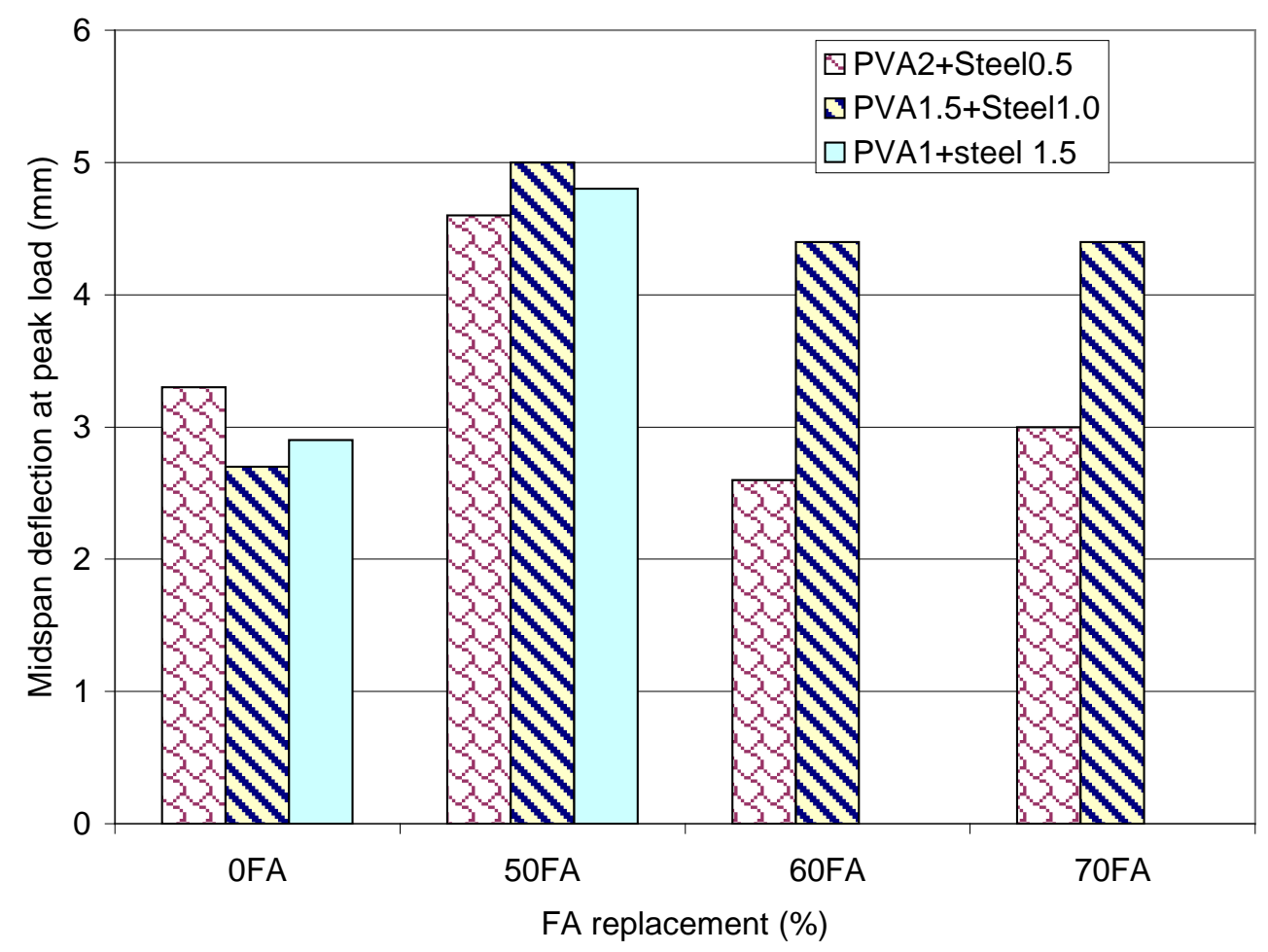

Fig. 11 Deflection at peak load for steel-PVA hybrid composites with and without fly ash. (Note: FA denotes Fly ash)

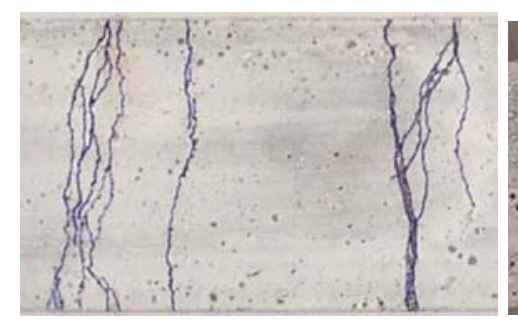

Steel 1.5+ PVA1.0

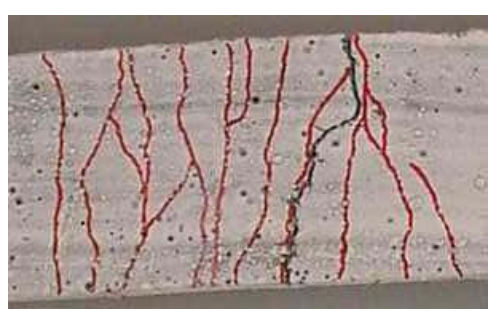

Steel 1.0+PVA1.5

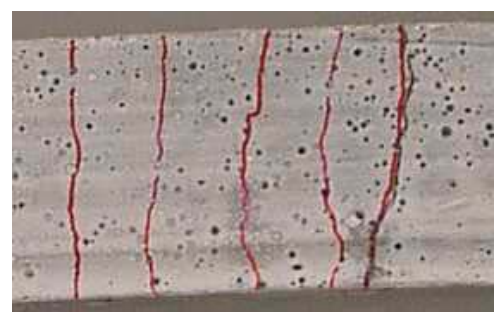

Steel 0.5+PVA2.0

Fig.12 Multiple cracking of steel-PVA hybrid fiber composites containing no fly ash.

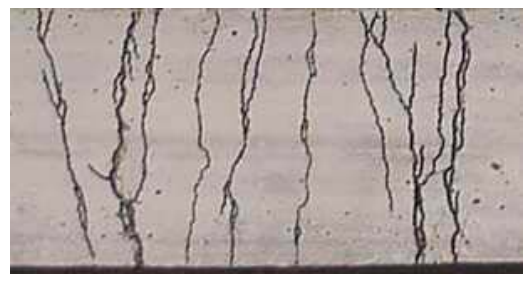

Steel 1.5+ PVA1.0

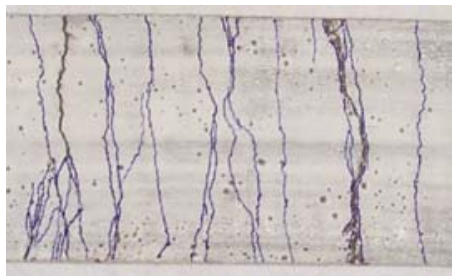

Steel 1.0+ PVA 1.5

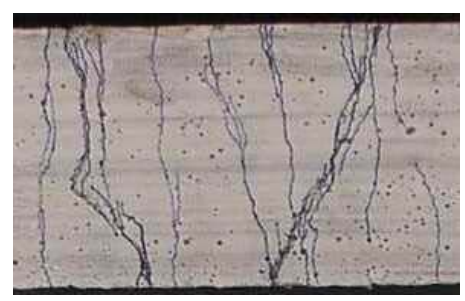

Steel $0.5+$ PVA2.0

Fig.13 Multiple cracking of steel-PVA hybrid fiber composites containing 50\% fly ash as partial replacement of cement (After Ahmed et al. [8]). 


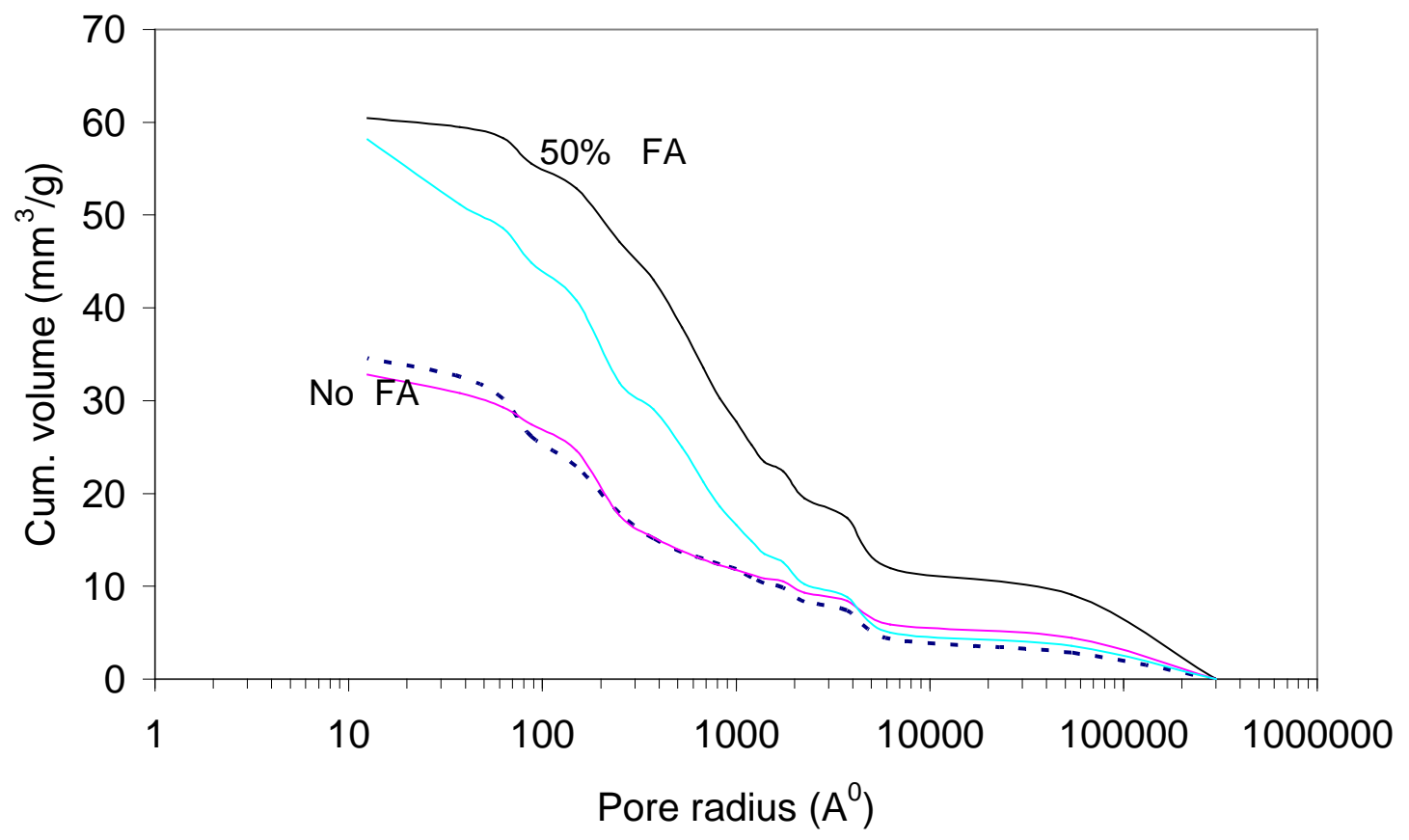

Fig. 14 Pore distribution of steel-PVA hybrid composites with and without fly ash. (Note: FA denotes Fly ash)

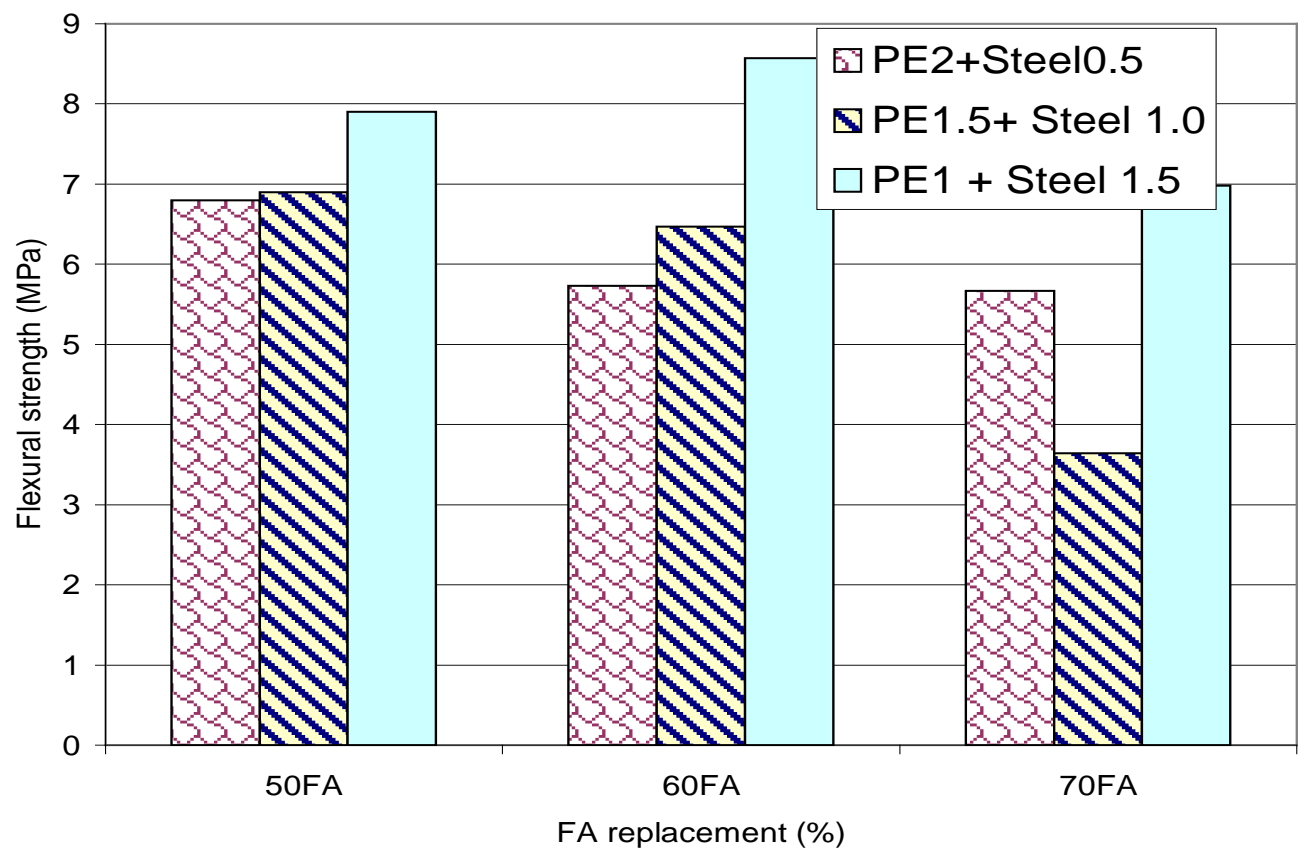

Fig. 15 Ultimate flexural strength of steel-PE hybrid composites with different fly ash contents. (Note: FA denotes Fly ash) 


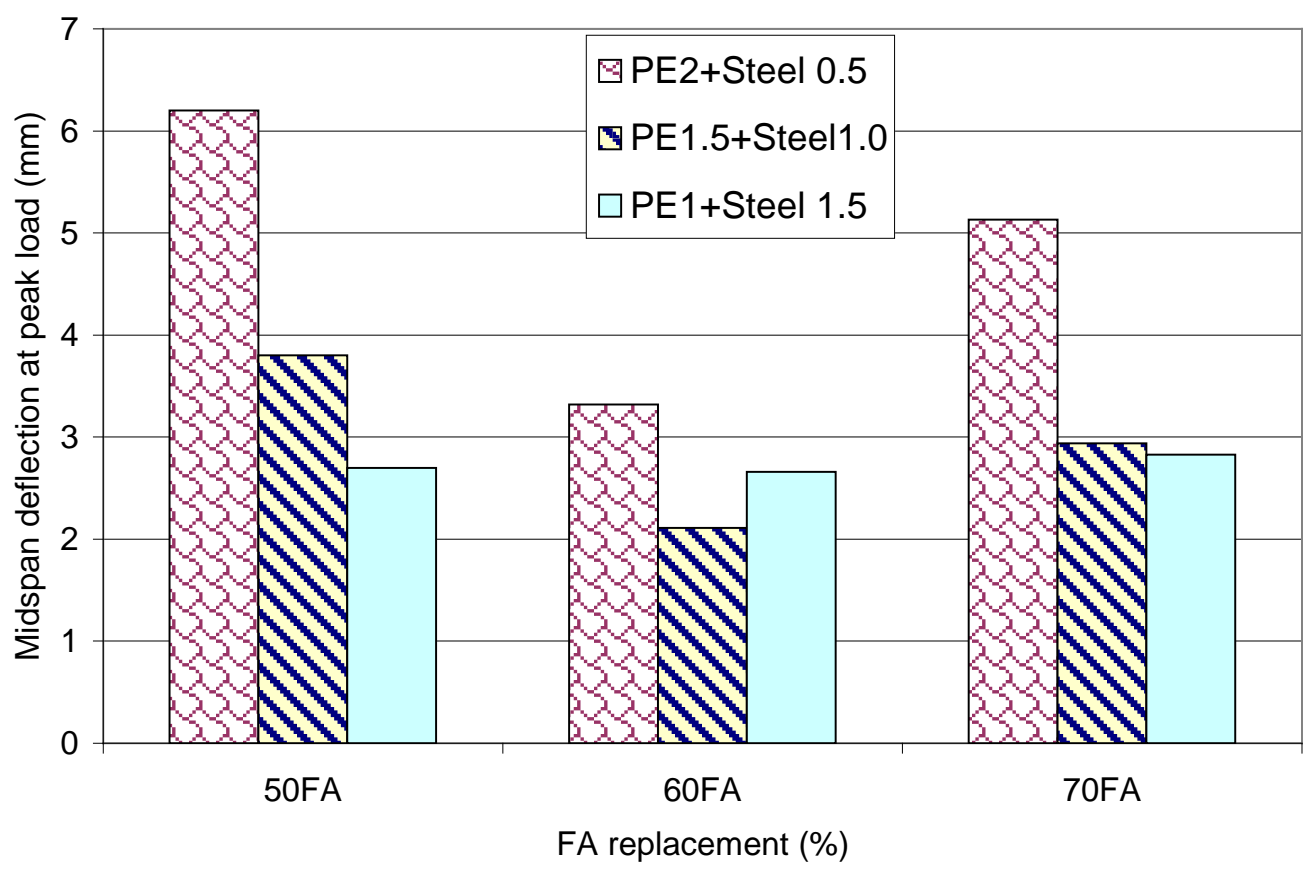

Fig. 16 Deflection at peak load for steel-PE hybrid composites with different fly ash contents. (Note: FA denotes Fly ash) 